\title{
LA PROPIEDAD DE LA TIERRA EN LA MONTAÑ̃ RIOJANA A MEDIADOS DEL SIGLO XVII**
}

\author{
José Ramón Moreno Fernández**
}

\section{INTRODUCCIÓN}

Una de las prioridades de este artículo es dejar en su justo lugar la importancia de la agricultura en una zona de montaña. Teniendo en cuenta que este era el subsector principal en el mundo rural de la Edad Moderna, merecerá la pena comprobar que en las sierras nunca reinaba en exclusiva e incluso, en casos muy notables, tan sólo ocupaba una modesta posición en la estructura económica de los pueblos. La extensión de la tierra cultivada alcanzaba cotas muy reducidas y los tipos de cultivos, así como sus rendimientos, estaban estrechamente limitados por las duras condiciones orográficas y climáticas.

Sin embargo, las dificultades agronómicas no fueron razón bastante para que la marginalidad estuviera siempre instalada en la sierra. A pesar de todo, pudieron convivir una pobre agricultura y una pujante población. Esta convivencia proporciona elementos añadidos para la reflexión. La dedicación agrícola en las sierras no podía ser más que secundaria, pero no era incompatible con una densidad de población apreciable. La presión demográfica, a diferencia de lo que sucedía en las llanuras, no había impulsado la expansión de los cultivos. El mundo rural, sobre todo el mundo rural de montaña, era mucho más que un simple escenario agrícola. De no ser por las otras oportunidades económicas con las que contaban los serranos, la subsistencia para un volumen de población tan abultado no sólo habría sido un grave problema, sino que se habría convertido en un imposible ${ }^{1}$.

\footnotetext{
* Trabajo realizado dentro del proyecto de investigación DGICYT, n ${ }^{\circ}$ PB95-0698, dirigido por J. L. Gómez Urdáñez.

*** Departamento de Estructura e Historia Económica y Economía Pública. Universidad de Zaragoza.

1. De todos modos, se viene cuestionando desde hace una década la linealidad del modelo clásico según el cual de forma unívoca el proceso de expansión agrícola se debe al aumento de la presión demográfica y, a la inversa, el descenso de la población se acompaña por un retroceso de los cultivos. Las relaciones automáticas pocas veces se ven refrendadas por la historia. Diversas reflexiones que se preguntan por todos los factores que influyen en el crecimiento agrícola en YUN, B. 1987: 510, y en BERNAL, A. M. 1989: 18 .
} 
En otro sentido, la marginalidad de la agricultura se puede afirmar más en términos económicos que sociales. Aunque su aportación al producto neto de las sierras se mantuviera en un segundo plano, la agricultura era una actividad no exclusiva, pero que absorbía una parte de los esfuerzos familiares en la mayoría de los hogares. Sin dejar de ser muy desigual, la propiedad de la tierra se encontraba muy extendida. En realidad los cultivos no trataban de perfeccionar una improbable autarquía, sino de atizar un elemento más que contribuyera a esa subsistencia familiar hecha de una combinación compleja de actividades múltiples. Dado que era el sector con mayores dificultades ecológicas, la subsistencia familiar estaba en el fondo de la naturaleza de una agricultura de montaña inserta en una economía más variada y plenamente orientada al mercado ${ }^{2}$. Bien claro lo dejaban en Ojacastro:

Porque las tierras están con tan poco casco por causa de los accidentes que dejan declarados [aguaceros, nublados y turbiones] que en otras partes se dejarían eriales y aquí se labran por no tener los naturales en qué ocuparse, si no en el ministerio de la labranza, y porque la paja sirve para alimento de sus ganados de cuya utilidad resulta parte de poderse mantener, aunque con estrechez ${ }^{3}$.

En este trabajo se pretende también comprobar de qué forma actuaban en las sierras riojanas las diferencias sociales en relación con la propiedad de la tierra. No se trata sólo de diferenciar las características de la propiedad noble y plebeya, eclesiástica y secular, labradora y campesina. Por encima de la sobrevalorada estratificación en estamentos, el enfoque elegido intentará distinguir simplemente a los poderosos, a los pequeños propietarios y a los miserables para, en el futuro, cruzar la información con los datos disponibles de las otras fuentes de ingresos; cruce que quizá sirva para desmentir o al menos para matizar la imagen social que proporciona el reparto de la propiedad agrícola.

De los nobles no vamos a hablar aquí como si fueran un grupo definido. El estamento nobiliario se componía de unos pocos titulados forasteros que mantenían posesiones en las sierras -nada demasiado relevante-; existía también un grupo de dones mejor delimitado por su capacidad económica que por la calidad de su sangre -son la totalidad de los grandes ganaderos y algunos hidalgos que pretenden conservar sus campanillas gracias a sus propiedades-, $y$ finalmente un nutrido número de hidalgos que se dedicaban al pastoreo, al trabajo de la tierra o que, incluso, eran pobres de solemnidad. En definitiva, como dijera la abuela de Sancho Panza, en este mundo -y en tantos otros- sólo había dos linajes, «el tener y el no tener». La hidalguía sólo era útil, y entonces lo era mucho, cuando iba acompañada de otros poderes ${ }^{4}$.

Finalmente, se pondrá el énfasis necesario en las considerables diferencias que presentaban los distintos lugares. Indudablemente, no se repetía de forma automática la misma estructura económica en todas las localidades. En efecto, existía en la Edad

2. En palabras de COPPOLA, G. 1989:502, en la montaña alpina italiana, «es una cerealicultura que da lo que puede y sólo su autoconsumo determina la persistencia de la agricultura".

3. AHPLR, Catastro, respuesta 12.

4. La cita del Quijote está tomada de PARKER, G. 1986: 22. Parecidas reflexiones podemos ver en DOMÍNGUEZ ORTIZ,A. 1996: 131-132. Si esto se podía afirmar a principios del siglo XVII, la cosa todavía estaba más clara en el XVIII. Sobre el valor de la hidalguía en el norte de España en la segunda mitad del XVIII VILAR, P. 1982: 65-67,ANES, G. 1989: 5-9, y DELGADO VIÑAS, C. 1983: 410. 
Moderna una notable especialización comarcal que repartía las funciones económicas con nitidez. Las villas atendían las actividades más monetarizadoras -la ganadería, la manufactura y el comercio de lanas y paños-, mientras las pequeñas aldeas mantenían una estructura más ruralizada, concentrada en la producción de granos y en la ganadería de labor, de vientre y de carne. Las desiguales relaciones de intercambio entre las minúsculas aldeas y las villas se reflejaban en un reparto de la propiedad de la tierra muy distinto y en una importancia también variable de la agricultura. De acuerdo con su situación en esta especialización comarcal, la actividad agrícola podía oscilar desde resultar fundamental para la reproducción económica de las localidades hasta rozar la marginalidad y ser casi prescindible para un porcentaje de la población significativo.

\section{LAS LIMTTACIONES AGRARIAS DE LA MONTAÑA.}

Para valorar la extensión superficial de los cultivos únicamente contamos con las respuestas generales del catastro. La información recogida en los estados generales, por estimar el producto de manera poco rigurosa y por mezclar medidas de superficie diferente, es menos fiable para este propósito. Dos preguntas del interrogatorio general, la $4^{\mathrm{a}}$ y la $10^{\mathrm{a}}$, se dirigían a indagar sobre la calidad y la extensión superficial de cada clase de tierra. Se ha realizado un vaciado exhaustivo de su contenido en toda La Rioja para comprobar, al fin, cómo también esta información plantea problemas de fiabilidad importantes. La veracidad de las respuestas no es mala, pero sí el detalle de las mismas. No disponemos de datos deliberadamente falsos o engañosos, pero tampoco contamos con todos los datos.

La variación en las medidas y en las clases y los rendimientos de las tierras también plantea estorbos para una correcta comparación entre los diversos lugares. La unidad de medida, en primera instancia, no es igual en todas las localidades 5 . La fanega -o la yugada en algunos enclaves de la Rioja Baja- admite diferencias de mucha consideración porque en La Rioja no se trata de una medida de superficie fija. En la mayoría de los casos se relaciona con la cantidad de terreno que se puede sembrar con una fanega de grano, con lo cual se ve afectada por la propia calidad de la tierra. En algunos pueblos procedieron a la medición, en varas castellanas cuadradas, de las fanegas que utilizaban en cada clase de tierra, pero en otros no se esforzaron hasta ese punto. Veamos por ejemplo la respuesta de Pazuengos, tan dilatada como vaga:

Que la medida que se usa en este término se llama fanega de sembradura, y que ignoran los pasos o varas de que se compone, pues se llama así porque lleva una de simiente siendo de primera calidad, si de segunda se le echa la misma simiente pero es más en la extensión, y si de tercera lleva la misma simiente pero coge más terreno; de manera que fanega de sembradura es la que lleva una de simiente, pero que

5. La importancia de las diferencias en las medidas de las tierras ha sido puesta de manifiesto en much as ocasiones. IBÁÑEZ RODRÍGUEZ, S. 1995:13-20, se ha ocupado de la «necesidad de medir»y los problemas de metrología en La Rioja en un trabajo que resuelve definitivamente esta cuestión previa. Para España SÁNCHEZ SALAZAR, F. 1988. 
la que es de segunda calidad se le echa igual simiente que a la de primera es más en tierra, y la de tercera más que la segunda y primera ${ }^{6}$.

Desde 2.592 hasta 5.005 varas castellanas cuadradas podian comprender las fanegas de la sierra, una variación de mucho bulto. Por esta razón, si se quieren ofrecer datos susceptibles de ser comparados con otras regiones, no cabe otro remedio que convertir las medidas al sistema métrico decimal, aun a sabiendas de que incluso las superficies originales declaradas pueden errar por mucho y, más aún, de que las equivalencias no siempre están bien fundamentadas'. De cualquier modo, las deficiencias de las fuentes tampoco deben paralizar el análisis, aunque conviene no perder la perspectiva del valor meramente indicativo que tienen estos ensayos.

En los casos concretos, la calidad de las respuestas depende de forma estrecha del celo desplegado por el juez subdelegado y por los peritos a la hora de resolverlas de forma más o menos explícita. Cuando se estudia en profundidad el catastro es fácil percibir hasta qué punto los jueces dejaron marcado su estilo en la confección de las averiguaciones. Uno de los peores fue D. Joseph Sáenz de Cabezón, quien ejecutó la encuesta en algunos pueblos de los Cameros Nuevo y Viejo -Almarza, Castañares, Montalbo, Nestares, Ribabellosa, Robres del Castillo y Torre-. En casi todos se omitió dar la equivalencia de las medidas locales y en todos, con la excusa de remitirse a los memoriales, falta el detalle en las respuestas 4 y 10 de las medidas de tierra de cada calidad que existían en los términos. No ha quedado más remedio que seleccionar las respuestas del medio centenar de localidades que recogieron suficientes pormenores de la dedicación de sus tierras ${ }^{8}$.

La extensión de los cultivos se reducía, con ciertas variaciones comarcales, al 17,5 por 100 de los territorios. Un resultado ciertamente pobre si lo contrastamos con las cifras que circulan por la historiografía para agregados administrativos más amplios: la

6. Como de costumbre, la calidad de las respuestas era muy diversa, desde la prolijidad de Viniegra de Abajo - «que en esta villa se usa de la medida que llaman fanega, cuya cabida no es igual en todas las tierras, según la calidad de ellas, porque la fanega de tierra de hortaliza de regadío por pie, de prados, de sembradura de secano que produce sin intermisión de primera calidad y que produce a tercero de la misma se compone de 2.809 varas castellanas cuadradas, que son 53 en cuadro; la de segunda calidad de cualquiera especie de tierra de 3.721, que son 61 en cuadro, y la de tercera calidad, en que entre la de dehesa, monte, eras o incultas por naturaleza o desidia, se compone de 4.761, que son 69 en cuadro»- hasta la dejadez de Lumbreras - «que el uso de medias de tierra que se usa en esta villa y sus aldeas es por la cantidad que de cada especie de grano se siembre en ella, sin que se verifique media por pasos o varas ni en otra formas-.

7. Naturalmente, el problema no se reduce sólo a la diversidad de medidas, sino que se agrava por las deficiencias en las mediciones, a veces de muchísima consideración. Jesús Briones, ingeniero jefe de la provincia de Logroño en fecha tan avanzada como 1928, señalaba cómo en casi todas las zonas de la provincia, los errores en las medidas eran abultadísimos, por ejemplo en la zona de Viniegra de Abajo: "esta zona está constituida por trece montes catalogados que figuran en él con 8.060 hectáreas de cabida total y estando con toda claridad sus límites, no ocurre lo mismo con sus cabidas, pues teniendo en cuenta que el tiempo que se tarda en recorretlo en diversas direcciones y por comparación con otras zonas en que se tienen datos precisos de las cabidas de los montes, se puede asegurar que la cabida efectiva es de tres veces la que figura en la actualidad» (Informe sobre la conveniencia de la repoblación forestal en la provincia de Logroño, p. 49, AHPLR, fuera de inventario). Como norma general, a no ser que las evidencias en contra sean irrefutables, los testimonios cualitativos de este estilo me parecen mucho más exactos que todas las operaciones basadas en estadísticas dudosas.

8. Las cifras se han convertido a hectáreas para facilitar la comparación con otras zonas o épocas en las que la fanega u otras medidas locales no tenían mucha presencia. 
superficie cultivada en la Corona de Castilla, por ejemplo, alcanzaba el 46 por 100 , aunque en la provincia de Soria se reducía hasta el 29,5 y en la Tierra de Soria aún descendía hasta el $23,75^{\circ}$. Naturalmente, en estos agregados se están mezclando zonas de montaña y de llano. Las cifras aparecen suavizadas ocultando los contrastes agroclimáticos. Si recurrimos a datos menos agregados, tenemos buenos términos de comparación en Cantabria -en el Valle de Mena el cultivo no superaba el 12 por $100 \mathrm{del}$ territorio- y dentro de la Tierra de Soria -en el sexmo de Frentes, donde sólo se cultivaba el 15,35 por 100 de su superficie ${ }^{10}$ - . Parece evidente la utilidad de optar por las comarcas agroclimáticas como marco de estudio capaz de matizar y enriquecer las macrocifras regionales ${ }^{11}$. Con toda probabilidad, la relación entre tierras incultas y cultivos era muy similar en todas las sierras castellanas y raramente se cultivaba más allá de la quinta parte de las superficies. Quizá menos, si tenemos en cuenta las extensiones actuales de los términos, casi siempre muy superiores a la suma de las medidas de tierra declaradas en el catastro.

En este sentido existe una evidencia que procede aclarar: los pueblos de La Demanda que proporcionaban datos de calidad tienen en la actualidad una extensión de 68.453 hectáreas, los de Cameros 39.227 y los de la Rioja Baja 42.761. En el catastro, sin embargo, la suma de todas las medidas de tierra supera por muy poco el 67 por 100 de la suma de aquéllas. Tal discrepancia no puede deberse a hipotéticas variaciones en las jurisdicciones de los términos, de las que no hay constancia y que, de haberse producido, habrían aumentado la superficie de unas localidades tanto como hubieran disminuido otras. Una parte del error se puede imputar a los repetidos desaciertos en las medidas, pero la razón más probable es que falten en las respuestas muchos terrenos sin cultivar -yermos desde el punto de vista fiscal-. Cualquiera de las dos razones actuaría en la misma dirección: sobrevalorando el peso global de las tierras cultivadas, sin duda menos susceptibles de ser ocultadas o mal medidas. Si corrigiéramos los resultados comparando el terreno de cultivo que aparece en el catastro con la extensión actual de los términos municipales la tierra de cultivo disminuiría su importancia porcentual todavía un poco más ${ }^{12}$.

En el cuadro 1 también se muestran importantes diferencias en el reparto de la tierra de cultivo que existía en la Demanda, los Cameros y la sierra de la Rioja Baja. Si las razones de tales discrepancias tuvieran que ver con la omisión de importantes porciones de terreno, la lectura del mayor porcentaje de dedicación agrícola de las sierras orientales podría matizarse. De hecho, en la Rioja Baja, es mayor la diferencia entre las extensiones que aparecen en el XVIII y la extensión actual. La cifra total que arroja el catastro, 25.442 hectáreas, apenas alcanza el 59 por 100 de la superficie que ocupan en la actualidad.

9. Los datos de la Corona de Castilla y de la provincia de Soria se desprenden de las cifras del GRUPO '75 1977: 85-86. La Tierra de Soria en PÉREZ ROMERO, E. 1995: 80.

10. Para Cantabria GARCía FERNÁNDEZ, J. 1975: 44 y para la Tierra de Soria PÉREZ ROMERO, E. 1995: 81 .

11. Casos como este sirven para apreciar en sus términos algunas afirmaciones como las del GRUPO '75 1977: 89, que terminaba por inferir, a partir de magnitudes agregadas, que Castilla presentaba «un paisaje agrario cuyos rasgos generales los constituían el predominio, en cuanto a superficie, de las tierras dedicadas a cultivo y labon. Lo que podía ser cierto para la Castilla del cereal -por ejemplo, para Tierra de Campos, donde el cultivo llegaba casi al 85 por 100 tal y como se demuestra en YUN, B. 1987:511- no lo era en absoluto para las sierras volcadas hacia la ganadería.

12. Este procedimiento ya se siguió en MORENO FERNÁNDEZ, J. R. 1994: 31-33. 
Cuadro 1. Distribución de la tierra en las sierras de La Rioja, 1750

\begin{tabular}{|c|c|c|c|c|c|c|c|c|}
\hline & \multicolumn{2}{|c|}{ Sierra Demanda } & \multicolumn{2}{|c|}{ Sierra Cameros } & \multicolumn{2}{|c|}{ Sierra R. Baja } & \multirow{2}{*}{$\begin{array}{c}\text { Totales } \\
\text { Has. }\end{array}$} & \multirow[b]{2}{*}{$\%$} \\
\hline & Has. & $\%$ & Has. & $\%$ & Has. & $\%$ & & \\
\hline \multicolumn{9}{|l|}{ Tierra cultivada } \\
\hline Hortaliza & 53,2 & 0,1 & 86,5 & 0,3 & 331,7 & 1,3 & 471,4 & 0,5 \\
\hline Secanocadañero & 317,1 & 0,7 & 185,1 & 0,6 & 170,1 & 0,7 & 672,3 & 0,7 \\
\hline Secano año y vez & 863,7 & 1,9 & $4.947,0$ & 15,6 & $5.461,1$ & 21,5 & $11.271,8$ & 11,0 \\
\hline Secano otras & $3.553,9$ & 7,9 & 821,5 & 2,6 & 0,0 & 0,0 & $4.375,4$ & 4,3 \\
\hline Otras* & 33,5 & 0,1 & 27,5 & 0,1 & 913,4 & 3,6 & 974,4 & 1,0 \\
\hline Prados & 123,1 & 0,3 & 24,3 & 0,1 & 8,8 & 0,0 & 156,2 & 0,2 \\
\hline Total 1 & $4.944,5$ & 11,0 & $6.091,9$ & 19,2 & $6.885,1$ & 27,1 & $17.921,5$ & 17,5 \\
\hline \multicolumn{9}{|l|}{ Tierra sin cultivar } \\
\hline Pastos & $31.929,3$ & 70,9 & $7.175,4$ & 22,7 & $10.966,8$ & 43,1 & $50.071,5$ & 49,0 \\
\hline Dehesas & 848,3 & 1,9 & $1.668,9$ & 5,3 & 220,2 & 0,9 & $2.737,4$ & 2,7 \\
\hline \multirow[t]{2}{*}{ Montes } & $6.726,5$ & 14,9 & $11.184,2$ & 35,3 & $1.770,5$ & 7,0 & $19.681,2$ & 19,3 \\
\hline & $39.504,1$ & 87,7 & $20.028,5$ & 63,3 & $12.957,5$ & 50,9 & $72.490,1$ & 71,0 \\
\hline \multicolumn{2}{|c|}{ Total $3(1+2) 44.448,6$} & 98,7 & $26.120,4$ & 82,5 & $19.842,6$ & 78,0 & $90.411,6$ & 88,5 \\
\hline \multicolumn{9}{|l|}{ Tierra improductiva } \\
\hline Yermadesidia & 0,0 & 0,0 & 256,0 & 0,8 & 274,4 & 1,1 & 530,4 & 0,5 \\
\hline Id. por naturaleza & 469,5 & 1,0 & $4.688,8$ & 14,8 & $4.705,9$ & 18,5 & $9.864,2$ & 9,7 \\
\hline \multirow{2}{*}{ Otras** } & 124,1 & 0,3 & 586,4 & 1,9 & 619,4 & 2,4 & $1.329,9$ & 1,3 \\
\hline & 593,6 & 1,3 & $5.531,2$ & 17,5 & $5.599,7$ & 22,0 & $11.724,5$ & 11,5 \\
\hline \multicolumn{3}{|c|}{ TOTAL $(3+4) 45.042,2 \quad 100,0$} & $31.651,6$ & 100,0 & $25.442,3$ & 100,0 & $102.136,1$ & 100,0 \\
\hline y vina & 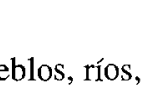 & 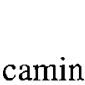 & , & 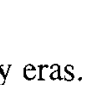 & & & & \\
\hline
\end{tabular}

Fuente: AHPLR, Catastro, respuestas generales.

De cualquier forma, aunque no conviene tomar al pie de la letra los totales que aparecen en el cuadro, es indudable un aumento de la dedicación agrícola conforme nos movemos en sentido oeste-este. Aumento que se ve corroborado con otros indicadores: también la relación entre la tierra cultivada y la población presenta una situación más favorable para la Rioja Baja. Con una densidad de población menor, en las sierras orientales correspondían 3,7 hectáreas de tierra cultivada a cada vecino mientras en la Demanda y en los Cameros la razón era de 2,4 hectáreas por vecino.

Las razones de estas diferencias se pueden localizar en varios factores. Tanto las condiciones naturales como la estructura económica presentaban diferencias que pueden contribuir a explicar una mayor o menor extensión de los cultivos. En la Rioja Baja las pendientes eran ligeramente más suaves y las temperaturas sufrían oscilaciones menos violentas. Ambos factores repercutían de forma muy directa en la dedicación agrícola (mapas 1 y 2). En la época, también la literatura disponible observaba de forma selectiva las comarcas serranas. Madoz (1850), por ejemplo, en su artículo dedicado a la provincia de Logroño era tajante al seleccionar el territorio que la conciencia popular ha designado como «sierra»:

Son considerables en esta provincia los terrenos yermos y baldíos, y casi no hay pueblo que no los tenga, siendo una de las causas del estado de decadencia de la agricultura, especialmente en la Sierra de Cameros. 

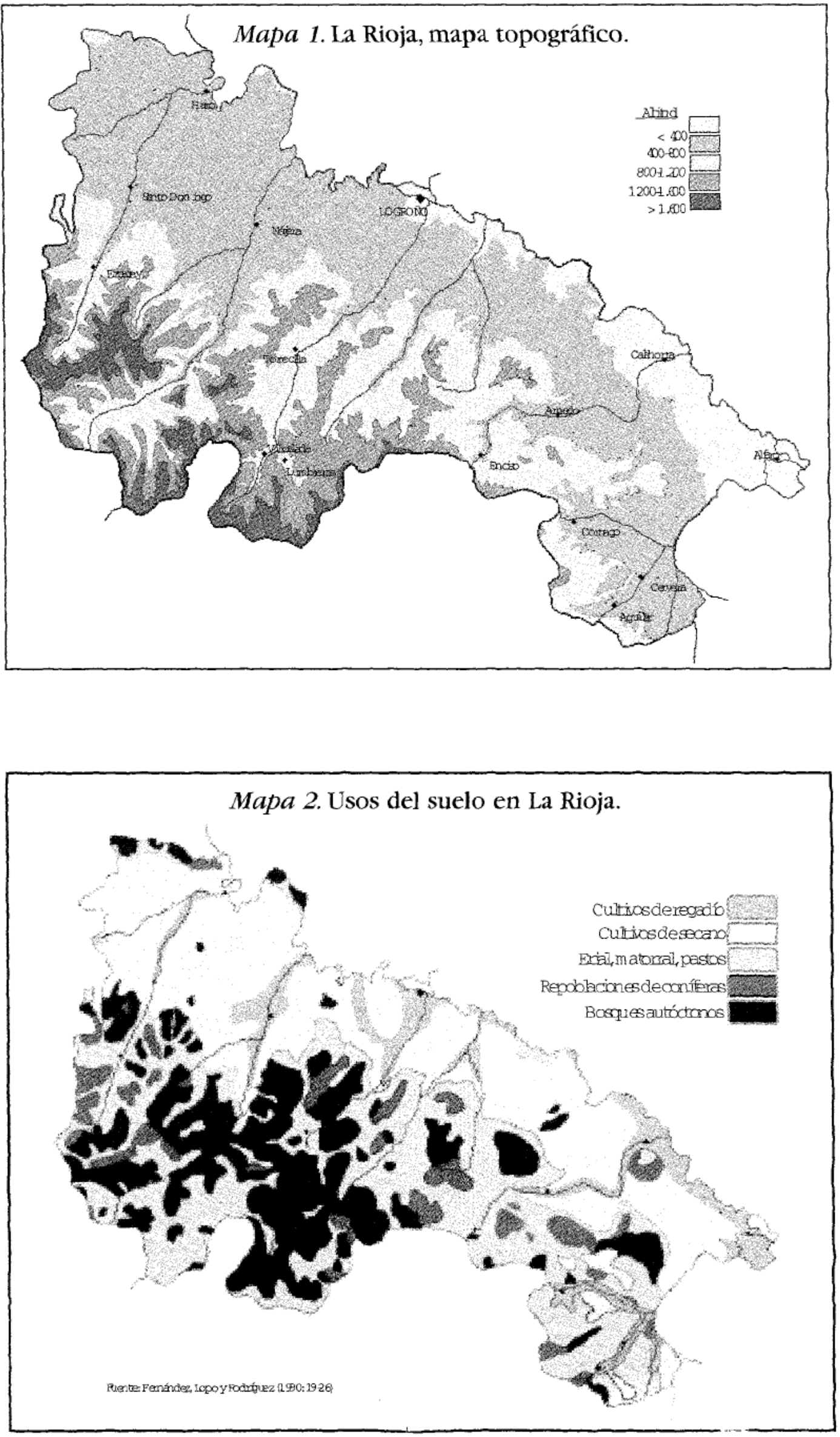
La abusiva dedicación a la ganadería trashumante de las sierras de Cameros y la Demanda actuaba en la misma dirección: restringiendo la agricultura a los ruedos de las poblaciones y reservando la mayor parte del territorio para el apacentamiento del ganado. La ausencia de ganaderos y cabañas trashumantes en la Rioja Baja aliviaba esta presión suplementaria sobre el terrazgo y relajaba el control sobre las superficies comunes permitiendo un crecimiento superior de los cultivos.

$\mathrm{Al}$ margen de las ligeras diferencias en las condiciones naturales, se podría afirmar una relación inversa entre la vocación agrícola de un término y la potencia de su ganadería, por lo demás bastante lógica si tenemos en cuenta que ambas actividades competían por la utilización del mismo territorio. Por ello los resultados de Cameros y la Demanda son mucho más pobres. No le faltaba razón al agrónomo Pérez Calvet cuando afirmaba que «la agricultura no debió desarrollarse cumplidamente [en Ortigosa de Cameros] sino a partir de $1780 »^{13}$. Mientras la ganadería trashumante fue la actividad más pujante no quedaba mucho espacio para ampliar cultivos y la población no veía forma de acceder a una propiedad suficiente - ni lo necesitaba de forma imperiosa, gracias a la importante demanda de fuerza de trabajo de las cabañas trashumantes-.

En definitiva, la agricultura no alcanzaba resultados muy brillantes. Escasa superficie cultivada en cada término, predominio del centeno y rendimientos de miseria componían las señas de identidad agrícolas de las sierras. Las dificultades ecológicas se sumaban en la dirección que marcaba la vocación pecuaria de la montaña. Ambos elementos se reforzaban y se retroalimentaban minimizando el papel de la agricultura incluso por debajo de lo que era esperable. Ahora bien, aun siendo todo esto cierto, también conviene resaltar que el trabajo de la tierra era una dedicación secundaria pero importante para todas las familias. La mayor parte de los serranos contaba con una pequeña huerta en la que cultivar algunas verduras, lo cual constituía un complemento alimenticio seguro, rico y muy barato. A la postre, todos buscaban la subsistencia en actividades económicas variopintas, pero también contaban con algunos ingresos derivados de actividades agrícolas o forestales que estaban repartidos de forma casi universal.

\section{LA PROPIEDAD DE LA TIERRA.}

Los estudios sobre propiedad de la tierra tienen una larga tradición en nuestro país. Éste ha venido siendo el pilar del análisis de la propiedad de los medios de producción, de forma coherente con la importancia que la agricultura ha tenido en la historia de España. Sin embargo, aun cuando sería descabellado no dar a la estructura de la propiedad la importancia que merece, tampoco se han de perder de vista los límites de las explicaciones basadas únicamente en ella. Como se viene advirtiendo recurrentemente, el mundo de la montaña es mucho más que agrícola. El nivel de vida, esto es la forma en la que podían vivir efectivamente las personas, dependía del conjunto de los ingresos generados por la unidad familiar.Y esto obliga a observar tanto la propiedad agraria como el conjunto de las actividades en las que se ocupaba parte del trabajo disponible: el pastoreo, la manufactura, la recogida de leña, el carboneo, la caza, la pesca, etcétera. Habida cuenta del tamaño medio de las explotaciones y de los patri-

13. Recogido en MARTÍNEZ OLMEDO, L. 1946: $1 \phi 4$. 
monios -a lo que hay que sumar todavía los pobres rendimientos-, muchos de los mayores propietarios de tierra no podrían incluirse entre los acomodados a no ser que reunieran también otros ingresos procedentes de actividades más dinámicas. Cuando en futuros trabajos crucemos los datos sobre propiedad de ganados e ingresos personales con los de propiedad de la tierra tendremos una imagen mucho más fiel que la que vamos a esbozar en este apartado. Hasta entonces, las conclusiones sobre la estructura de la propiedad de la tierra se referirán únicamente a un medio de producción que, en estas sierras, distaba mucho de resultar esencial.

Para el estudio de la propiedad de la tierra hay que recurrir a las respuestas particulares, donde se detallan, una a una, todas las parcelas de tierra, recogiendo su calidad, su cabida y los linderos. Mediante el vaciado sistemático de una muestra de varios pueblos tenemos una imagen suficiente de las líneas básicas de la propiedad serrana ${ }^{14}$. El problema básico de esta fuente es que sólo recoge las propiedades en cada término municipal y deja fuera las tierras que algunos propietarios pudieran tener en otras jurisdicciones. Esto puede falsear la imagen obtenida. Para calibrar la importancia de esta circunstancia, se ha separado el análisis de las tierras en manos de forasteros.

También he analizado separadamente las propiedades territoriales de los eclesiásticos. Se trata de un grupo muy bien delimitado que tiene una característica común de gran interés: casi todas las tierras del clero -con la excepción de algunas patrimoniales y muy pocas beneficiales- estaban cedidas en arrendamiento, por lo que tamjién contribuían a la subsistencia de las familias arrendatarias.

\subsection{El predominio de la pequeña propiedad.}

En una primera aproximación vamos a calcular cuántos vecinos legos eran propietarios de tierras. En el cuadro 2, se compara el número de propietarios con el de recinos. Se han separado las aldeas de las villas, porque, como se puede observar, prejentan diferencias sustantivas. La comparación entre el porcentaje de propietarios sobre el total del vecindario en las aldeas y en las villas es sumamente instructiva. En iodos los casos, las villas recogen peores resultados como fruto de una estructura ecoaómica más compleja.

En términos generales, un número muy importante de los vecinos era propietario $\forall$, por tanto, se beneficiaba del producto del cultivo. Tomando como referencia esta muestra, que incluye a más de 2.000 vecinos, algo más de los dos tercios de todos los serranos contaban, poco o mucho, con la agricultura como un elemento de apoyo. En as villas el porcentaje se reducía de forma significativa a poco más de la mitad, pero en las aldeas la propiedad era casi universal, todos los vecinos -salvo contadas excepziones- eran propietarios y cultivadores.

Así venía sucediendo también en toda Castilla. La relación entre labradores y joraaleros fluctuaba desde las áreas más propicias para el cultivo agrícola, donde los jor-

14. Los pueblos elegidos han sido Ezcaray, Lumbreras, Ortigosa, Soto, Villoslada y Viniegra de Abajo, :odos ellos con sus respectivas aldeas. Entre todos suman 27 núcleos de población, unos 8.178 habitantes $\gamma$ una superficie de 542,4 kilómetros cuadrados, es decir el 23,4 por 100 de la población y más de la cuara parte del territorio de las sierras. 
naleros eran mayoría, hasta la montaña, en la que los propietarios son muchos más ${ }^{15}$. El predominio de los pequeños propietarios en la montaña no carece de lógica. La subsistencia familiar y la resistencia a la emigración eran los únicos incentivos capaces de explicar una agricultura que se desarrolla contra corriente. De hecho, hay quien la ha calificado como una "exigencia inevitable» de la montaña ${ }^{16}$. En realidad, había otra razón que explicaba la escasez de los jornaleros. Habida cuenta de los rendimientos que se lograban en las sierras, poco margen debía quedar para costear mano de obra jornalera. Como decían en Quintanar de Rioja

si se hace regulación de lo que queda para el labrador, solamente sale a su favor aquella porción que se le diera de jornal si hubiese quien le ocupase en este ministerio ${ }^{17}$.

Cuadro 2. Los propietarios de tierra en las tierras de La Rioja, 1750

\begin{tabular}{|c|c|c|c|}
\hline & Vecinos* & Propietarios & $\%$ \\
\hline Ezcaray & 172 & 79 & 45,93 \\
\hline Lumbreras & 209,5 & 125 & 59,67 \\
\hline Ortigosa & 269,5 & 156 & 57,88 \\
\hline Soto & 454,5 & 183 & 40,26 \\
\hline Villoslada & 303,5 & 184 & 60,63 \\
\hline Viniegra de Abajo & 136,5 & 113 & 82,78 \\
\hline Aldeas deEzcaray & 157,5 & 173 & 109,84 \\
\hline Aldeas de Lumbreras & 163 & 181 & 111,04 \\
\hline Aldeas de Ortigosa & 137,5 & 141 & 102,55 \\
\hline Aldea de Soto & 89,5 & 78 & 87,15 \\
\hline Total villas & $1.545,5$ & 840 & 54,35 \\
\hline \multirow[t]{2}{*}{ Total aldeas } & 547,5 & 573 & 104,66 \\
\hline & 2.093 & 1.413 & 67,51 \\
\hline
\end{tabular}

* El número de vecinos recoge a las viudas contadas como medio vecino. Por eso el porcentaje de propietarios puede ser superior a 100.

Fuente: AHPLR, Catastro, Respuestas particulares y libros de lo personal.

Por eso eran más frecuentes los baratos criados de labranza que los jornaleros. De corta edad, conviviendo en el domicilio del amo, aquéllos eran utilizados para todas las labores de la casa y su remuneración superaba por muy poco el coste de la comida y el vestido.

15. MARCOS MARTÍN,A. 1989: 160.

16. COPPOLA, G. 1989: 500. También señala que "sólo la pequeña hacienda de cultivadores directos se arriesga a soportar, con un gran empleo de trabajo, la puesta en cultivo de terrenos dificiles por su posición, por la calidad de su suelo, o por la altura».

17. AHPLR, Catastro, respuesta 12. 
Ahora bien, tampoco hay que exagerar. La importancia de la pequeña propiedad y su capacidad para lograr la subsistencia de las familias propietarias dependía también de forma muy directa de factores sociales e institucionales. La existencia de comunales, por ejemplo, permitía reducir el área de cultivo reservando importantes superficies para el aprovechamiento ganadero o forestal en común. También el control señorial sobre las tierras podía limitar la expansión agraria. En áreas de montaña europeas en las que el peso del feudalismo señorial no se había relajado, podía ser más ventajoso para el señor explotar los pastos o la madera de los terrenos sin cultivar que permitir su fraccionamiento para ponerlas en labor. En La Rioja, el predominio de los pequeños propietarios sobre un número reducido de jornaleros es consecuencia en parte del limitado poder de los señores, pero sobre todo hay que tener en cuenta que se produce con un concepto muy poco preciso de labrador. Labrador es todo aquel que dice serlo aunque, en muchas ocasiones, su dotación patrimonial lo desmienta ${ }^{18}$. Por tanto, el labrador no es un individuo que cuenta con una explotación suficiente para la subsistencia familiar. En ocasiones, la amplitud de sus explotaciones tampoco les diferencia demasiado de los jornaleros. Es probable que, en ciertos casos, la categoría labrador denuncie más una aspiración de independencia económica y social que la posesión de un patrimonio.A pesar de ello, la abundancia de propietarios y la simétrica escasez de jornaleros ha servido, junto a la importancia del comunal, para contaminar la imagen de la montaña con falsos tintes igualitarios en la conciencia colectiva. Sigue siendo conveniente resaltar que este dato, por sí solo, no indica nada acerca del nivel de vida en unas y otras zonas, el cual dependía del total de los ingresos y no de la propiedad de una minúscula huerta ${ }^{19}$.

En el cuadro 3 se ha distribuido a los vecinos propietarios en grupos, de acuerdo con la importancia superficial de sus heredades. Con la intención de recoger una instantánea más representativa y homogénea, se han excluido del conjunto de propietarios los forasteros, el concejo y los eclesiásticos. En términos generales, las explotaciones se encontraban extraordinariamente fragmentadas. La unidad de cultivo, calculada a través de la cabida de las parcelas medias, rara vez superaba la quinta parte de una hectárea. Finalmente, la propiedad también estaba muy repartida, revelando un entramado social complejo y no exento de desigualdades. Los tres factores invitaban a realizar una separación en grupos que sin duda sorprenderá a los investigadores acostumbrados a zonas en las que la agricultura tenía un peso mayor. Sin embargo, en las sierras, donde ésta se simultaneaba con otras actividades y en muchas familias tenía un peso reducido, la estructura de las explotaciones familiares obligaba a distinguir hasta 6 grupos, de los cuales los 5 primeros no alcanzaban las 5 hectáreas en propiedad y los 3 primeros se encontraban por debajo de 1 hectárea.

Para empezar, también en este cuadro se aprecia una importante diferencia entre las villas y las aldeas. Si juzgáramos a partir de los resultados que se obtienen del estu-

18. Sospecho que algo parecido puede suceder en la mayor parte de los censos como el de Ensenada y el de Godoy. Convertir una respuesta vaga en una definición sociológica muy cerrada es, cuando menos, arriesgado. De hecho, en el catastro nos encontramos con algunos "labradores" que incomprensiblemente no poseen ni tierra ni ganado de labor.

19. VILAR, P. 1982: 70-72, observaba la diferencia entre Galicia y León, con un porcentaje de jornaleros inferior al 5 por $100, y$ Córdoba con hasta un 86 por 100 y concluía: «se trata de dos polos opuestos de la miseria rural». 
Cuadro 3. Estructura de la propiedad de la tierra en las sierras, 1750. (vecinos).

\begin{tabular}{|c|c|c|c|c|c|c|c|c|c|}
\hline \multirow[b]{2}{*}{ Áreas } & \multicolumn{2}{|c|}{ Propietarios } & \multicolumn{2}{|c|}{ Fincas } & \multicolumn{2}{|c|}{ Extensión } & \multirow{2}{*}{$\begin{array}{l}\text { Ext. media } \\
\text { áreas }\end{array}$} & \multicolumn{2}{|c|}{ Producto } \\
\hline & $\mathrm{n}^{\mathrm{o}}$ & $\%$ & $\mathrm{n}^{\mathrm{o}}$ & $\%$ & hectáreas & $\%$ & & reales & $\%$ \\
\hline \multicolumn{10}{|l|}{ Villas } \\
\hline $0-20$ & 198 & 23,6 & 247 & 3,2 & 8,9 & 0,6 & 3,6 & $1.204,5$ & 0,9 \\
\hline $20,1-60$ & 158 & 18,8 & 468 & 6,0 & 58,8 & 3,9 & 12,6 & $4.486,2$ & 3,4 \\
\hline $60,1-100$ & 108 & 12,9 & 549 & 7,1 & 83,5 & 5,6 & 15,2 & $7.048,2$ & 5,4 \\
\hline $100,1-200$ & 166 & 19,8 & 1.478 & 19,0 & 242,9 & 16,3 & 16,4 & $20.413,4$ & 15,5 \\
\hline $200,1-500$ & 142 & 16,9 & 2.464 & 31,7 & 430,2 & 28,8 & 17,5 & $36.317,2$ & 27,6 \\
\hline$>500$ & 68 & 8,1 & 2.559 & 33,0 & 668,5 & 44,8 & 26,1 & $62.116,8$ & 47,2 \\
\hline Total villas & 840 & 100,0 & 7.763 & 100,0 & 1492,8 & 100,0 & 19,2 & $131.586,3$ & 100,0 \\
\hline \multicolumn{10}{|l|}{ Aldeas } \\
\hline $0-20$ & 61 & 10,6 & 87 & 0,8 & 3,1 & 0,2 & 3,6 & 340,4 & 0,3 \\
\hline $20,1-60$ & 68 & 11,9 & 308 & 2,9 & 26,5 & 2,0 & 8,6 & $1.826,0$ & 1,9 \\
\hline $60,1-100$ & 75 & 13,1 & 629 & 5,8 & 60,0 & 4,4 & 9,5 & $4.310,4$ & 4,4 \\
\hline $100,1-200$ & 119 & 20,8 & 1.928 & 17,9 & 175,5 & 13,0 & 9,1 & $12.961,0$ & 13,3 \\
\hline $200,1-500$ & 178 & 31,1 & 4.839 & 44,9 & 574,0 & 42,4 & 11,9 & $40.862,7$ & 41,9 \\
\hline$>500$ & 72 & 12,6 & 2.985 & 27,7 & 514,1 & 38,0 & 17,2 & $37.198,4$ & 38,2 \\
\hline Total aldeas & 573 & 100,0 & 10.776 & 100,0 & 1353,2 & 100,0 & 12,6 & $97.499,0$ & 100,0 \\
\hline \multicolumn{10}{|c|}{ Total de villas y aldeas } \\
\hline $0-20$ & 259 & 18,3 & 333 & 1,8 & 12,0 & 0,4 & 3,6 & $1.544,9$ & 0,7 \\
\hline $20,1-60$ & 226 & 16,0 & 775 & 4,2 & 85,3 & 3,0 & 11,0 & $6.312,2$ & 2,8 \\
\hline $60,1-100$ & 183 & 13,0 & 1.178 & 6,4 & 143,5 & 5,0 & 12,2 & $11.358,6$ & 5,0 \\
\hline $100,1-200$ & 285 & 20,2 & 3.406 & 18,4 & 418,4 & 14,7 & 12,3 & $33.374,4$ & 14,6 \\
\hline $200,1-500$ & 320 & 22,6 & 7.303 & 39,4 & $1.004,2$ & 35,3 & 13,8 & $77.189,9$ & 33,7 \\
\hline$>500$ & 140 & 9,9 & 5.544 & 29,9 & $1.182,6$ & 41,6 & 21,3 & $99.315,2$ & 43,4 \\
\hline Total sierras & 1.413 & 100,0 & 18.539 & 100,0 & $2.846,0$ & 100,0 & 15,4 & $229.085,3$ & 100,0 \\
\hline
\end{tabular}

Fuente: AHPLR, Catastro, Respuestas particulares

dio de la estructura de la propiedad, podríamos contraponer unas aldeas igualitarias frente a unas villas en las que las diferencias de riqueza eran notables. Basten algunos datos: los propietarios de más de 2 hectáreas son el 25 por 100 en las villas y acaparan el 75 por 100 del producto bruto, en las aldeas son el 44 por 100 y controlan el 81 del producto; en las villas sólo el 45 por 100 de los propietarios poseía más de 1 hectárea, en las aldeas este porcentaje se elevaba hasta el 64 por 100.

Así pues, la estructura de la propiedad de la tierra estaba menos polarizada en las aldeas que en las villas. Ahora bien, sería apresurado concluir demasiadas cosas sobre los niveles de vida en unas y otras localidades. En primer lugar, como se veía en el capítulo anterior, las villas se configuraban al interior de las sierras como polos de atracción de población. En efecto, la mayor parte de los grandes ganaderos y de los comerciantes pañeros tenía su residencia en los núcleos más poblados y su mayor movilidad económica abría multitud de posibilidades laborales en el pastoreo y en la manufactura. En la especialización local del trabajo, las aldeas quedaban en una situación mucho más ruralizada, como productoras de grano y carne casi en exclusiva. En el futuro habrá ocasión de profundizar en este asunto a través del estudio del reparto de la ganadería, pero se puede adelantar que las cabañas trashumantes reinaban en solitario en las villas, mientras en las aldeas casi estaban ausentes en favor del ganado de crianza para reponer la labranza y el ganado de transporte. 
Las cosas incluso se pueden plantear de forma inversa. En este contexto, para una familia que residiera en Soto o en Villoslada la propiedad de menos de una hectárea de tierra podía ser suficiente. En cierto modo, incluso con la posesión de una pequeña huerta, si había oportunidad de emplearse en el pastoreo o en alguna manufactura, se podía sobrevivir sin complicaciones. La riqueza de posibilidades que ofrecía el mercado de trabajo en estos enclaves liberaba a la tierra de su papel principal. En una aldea, sin embargo, donde la economía no presentaba el mismo dinamismo, la propiedad de la tierra seguía siendo el instrumento que definía la riqueza y la pobreza.

Los pequeños y los ínfimos propietarios tenían un mayor número de fincas separadas por unidad de superficie, lo cual debía sin duda complicar la labranza con desplazamientos a veces importantes. La costumbre de organizar el terrazgo en hojas y la extensión de las tierras cultivadas a segundo y a tercer año, obligaban también a fraccionar los patrimonios en minúsculas parcelas situadas en cada una de las hojas. La calidad de las parcelas era como media inferior a la de los mayores propietarios con la excepción de los más pequeños, grupo en el que la propiedad de huertas en hogares dedicados a actividades no agrícolas elevaba el producto de sus explotaciones.

Indudablemente, las estrategias patrimoniales de los poderosos diferían de forma importante de las costumbres de división igualitaria de las herencias vigentes para la mayoría de la población. El tamaño de la unidad de explotación de aquéllos era sustancialmente mayor, así como su presencia en las mejores tierras, y ello sólo podía ser consecuencia de una voluntad explícita de evitar la desintegración de los patrimonios. La presencia de algunos mayorazgos y el destino a la iglesia de algunos de los hijos de las familias más importantes reforzaban esta tendencia.

Ahora bien, los grandes propietarios ni eran muchos ni poseían extensiones demasiado grandes. Es cierto que entre los 11 mayores propietarios, todos los que poseían más de 20 hectáreas de tierras en la muestra elegida, controlaban el 8 por 100 de la tierra cultivada y el 10 por 100 del producto. Pero patrimonios de 20 ó 30 hectáreas tampoco se pueden calificar de exagerados. Sólo dos propietarios, D. Baltasar García

Cuadro 4. Los mayores propietarios de tierras en la muestra, 1750.

\begin{tabular}{llrrrr}
\hline \multicolumn{1}{c}{ Propietarios } & \multicolumn{2}{c}{ Fincas } & \multicolumn{2}{c}{ Producto } \\
& Término & $\mathrm{n}^{\mathbf{0}}$ & hectáreas & ext. media & reales \\
\hline D. Bernardo Moredas & Soto & 6 & 20,3 & 3,39 & $1.376,2$ \\
D. Juan Esteban de Tejada Manso de Velasco & Ortigosa & 72 & 20,4 & 0,28 & $2.591,7$ \\
Cabildo eclesiástico de Villoslada & Villoslada & 71 & 20,5 & 0,29 & $2.030,3$ \\
D. Manuel de Barrenechea y Soria & Ezcaray & 66 & 20,6 & 0,31 & $1.625,5$ \\
D. Pedro Pascasio Zapata Sánchez Salvador & Lumbreras & 42 & 20,6 & 0,49 & $2.010,0$ \\
D. Francisco Antonio Sánchez Salvador & Lumbreras & 54 & 23,1 & 0,43 & $2.270,9$ \\
D. Mateo Pérez Andrés & Ortigosa & 108 & 25,0 & 0,23 & $3.020,0$ \\
D. Matías García del Valle & Villoslada & 99 & 33,3 & 0,34 & $3.354,1$ \\
Herederos de D. Antonio Fdez de Velasco & Villoslada & 91 & 34,8 & 0,38 & $3.552,1$ \\
D. Baltasar García del Valle, vecino Torrecilla & Villoslada & 130 & 50,1 & 0,39 & $5.218,7$ \\
Cabildo eclesiástico de Ezcaray & Ezcaray & 418 & 55,3 & 0,13 & $3.929,2$ \\
\hline Total & & 1157 & 324,0 & 0,28 & $30.978,8$ \\
\hline
\end{tabular}

Fuente: AHPLR, Catastro, respuestas particulares. 
JOSÉ RAMÓN MORENO FERNÁNDEZ

Cuadro 5. Estructura de la propiedad de la tierra en Soto, 1750

\begin{tabular}{|c|c|c|c|c|c|c|c|c|c|}
\hline \multirow{2}{*}{$\begin{array}{c}\text { Tamaño } \\
\text { (áreas) }\end{array}$} & \multicolumn{2}{|c|}{ Propietarios } & \multicolumn{2}{|c|}{ Fincas } & \multicolumn{2}{|c|}{ Extensión } & \multirow{2}{*}{$\begin{array}{c}\text { Ext. media } \\
\text { (áreas) }\end{array}$} & \multicolumn{2}{|c|}{ Producto } \\
\hline & $\left(n^{\circ}\right)$ & $\%$ & $\left(n^{o}\right)$ & $\%$ & hectáreas & $\%$ & & rs & $\%$ \\
\hline $0-20$ & 36 & 19,7 & 42 & 3,7 & 2,6 & 0,9 & 6,3 & 384,7 & 1,5 \\
\hline $20,1-60$ & 49 & 26,8 & 95 & 8,4 & 17,9 & 6,0 & 18,8 & $1.456,0$ & 5,5 \\
\hline $60,1-100$ & 24 & 13,1 & 83 & 7,3 & 18,7 & 6,2 & 22,5 & $1.497,2$ & 5,7 \\
\hline $100,1-200$ & 35 & 19,1 & 197 & 17,3 & 49,3 & 16,4 & 25,1 & $4.575,6$ & 17,4 \\
\hline $200,1-500$ & 26 & 14,2 & 340 & 29,9 & 78,6 & 26,2 & 23,1 & $6.623,9$ & 25,1 \\
\hline$>500$ & 13 & 7,1 & 379 & 33,4 & 133,5 & 44,4 & 35,3 & $11.800,4$ & 44,8 \\
\hline Total & 183 & 100,0 & 1.135 & 100,0 & 300,6 & 100,0 & 26,5 & $26.337,7$ & 100,0 \\
\hline
\end{tabular}

Fuente: AHPLR, Catastro, Respuestas Particulares.

del Valle y el cabildo de beneficiados de Ezcaray, sobrepasaban nítidamente ese nivel y superaban, por muy poco, las 50 hectáreas.

Por lo demás, resulta significativo que entre estos 11, se produjeran coincidencias de apellidos. Los García del Valle y los Sánchez Salvador -a los que nos encontramos como grandes ganaderos- eran dos de las familias más poderosas de la sierra y, como solía suceder, procuraban acaparar tanto tierras como casas o ganados o edificios destinados a la manufactura, etc.

Así como las aldeas presentan todas una estructura de la propiedad muy similar, en las villas se podían ver algunas variaciones respecto de la tendencia general en cuanto a su estructura económica. Sin embargo, las desigualdades en el terreno de la propiedad de la tierra estaban siempre presentes. Aun a riesgo de resultar un poco reiterativo vamos a analizar con detenimiento el reparto de la propiedad de la tierra en dos villas muy diferentes: Soto y Viniegra de Abajo. El primero era el más introducido en el mercado. La manufactura y el comercio ocupaban un lugar muy principal en su escenario económico. Viniegra de Abajo, por el contrario, se dedicaba casi de forma exclusiva al pastoreo y la agricultura.

Soto sin duda era la economía serrana más volcada hacia la manufactura y el comercio. En este sentido, constituye un extremo que lo convierte en un ejemplo poco representativo aunque, no obstante, reviste el interés de ser uno de los centros económicos más dinámicos de Cameros. Como se indicaba más arriba, sólo el 40 por 100 de los vecinos posé́a tierras -en realidad un poco menos, porque el total de los cabezas de casa si contamos las viudas como hogares enteros asciende a 485, cifra que rebajaría el porcentaje de propietarios al 37,7 por 100-. También el reparto era el más desigual de las sierras: casi el 60 por 100 de los propietarios se contentaba con el 13 por 100 de la extensión y del producto agrícola. En el extremo contrario, el 21 por 100 de los propietarios acumulaba el 70 por 100 de la superficie cultivada y el 61,8 por 100 del producto agrícola.

A través de Viniegra de Abajo, pueblo de la sierra de la Demanda, se pueden ilustrar las condiciones sociales en las que se desenvolvía otra parte de la agricultura serrana (cuadro 6). La distribución y el reparto de la tierra son bastante representativos de las situaciones habituales en las villas de pequeño tamaño, a medio cami- 
LA PROPIEDAD DE LA TIERRA EN LA MONTAÑA RIOJANA A MEDIADOS DEL SIGLO XVIII

Cuadro 6. Estructura de la propiedad de la tierra en Viniegra de Abajo, 1750

\begin{tabular}{|c|c|c|c|c|c|c|c|c|c|}
\hline \multirow{2}{*}{$\begin{array}{l}\text { Tamaño } \\
\text { (áreas) }\end{array}$} & \multicolumn{2}{|c|}{ Propietarios } & \multicolumn{2}{|c|}{ Fincas } & \multicolumn{2}{|c|}{ Extensión } & \multirow{2}{*}{$\begin{array}{c}\text { Ext. media } \\
\text { (áreas) }\end{array}$} & \multicolumn{2}{|c|}{ Producto } \\
\hline & $\left(n^{o}\right)$ & $\%$ & $\left(n^{o}\right)$ & $\%$ & hectáreas & $\%$ & & rs & $\%$ \\
\hline $0-20$ & 17 & 15,0 & 28 & 1,7 & 1,2 & 0,7 & 4,2 & 70,7 & 0,7 \\
\hline $20,1-60$ & 28 & 24,8 & 145 & 8,7 & 9,3 & 5,8 & 6,4 & 490,2 & 5,1 \\
\hline $60,1-100$ & 13 & 11,5 & 167 & 10,0 & 10,4 & 6,5 & 6,2 & 560,1 & 5,8 \\
\hline $100,1-200$ & 27 & 23,9 & 445 & 26,7 & 37,1 & 23,0 & 8,3 & $1.757,6$ & 18,1 \\
\hline $200,1-500$ & 21 & 18,6 & 562 & 33,7 & 54,6 & 33,8 & 9,7 & $2.697,7$ & 27,8 \\
\hline$>500$ & 7 & 6,2 & 322 & 19,3 & 48,7 & 30,2 & 15,1 & $4.128,9$ & 42,5 \\
\hline Total & 113 & 100,0 & 1.669 & 100,0 & 161,4 & 100,0 & 9,7 & $9.705,2$ & $\overline{100,0}$ \\
\hline
\end{tabular}

Fuente: A.H.P.L., Catastro, Respuestas Particulares.

no entre los emplazamientos más poblados y las minúsculas aldeas. El vecindario, en 1752, ascendía a 123 vecinos y 16 viudas, sin contar a los eclesiásticos: un clérigo y dos beneficiados. Pues bien, entre los vecinos seculares, hasta 113 poseían alguna suerte de tierra. La estructura de la propiedad sin embargo, no dejaba de mostrar algunas desigualdades. Poco más del 6 por 100 de los propietarios gozaba de patrimonios superiores a las 5 hectáreas, controlando más del 30 por 100 de la extensión cultivada y más de dos quintas partes del producto. En el lado de los pobres y los miserables, más de la mitad de los vecinos disponía de propiedades inferiores en su conjunto a la hectárea, lo que alcanzaba solamente un breve 13 por 100 de la tierra cultivada del término municipal y menos del 12 por 100 del producto.

De cualquier modo, en toda la muestra, tan sólo los 140 propietarios de más de 5 hectáreas -el 10 por 100 - podían confiar en mantener a una familia con sus tierras y, no obstante, muchos de ellos además se veían obligados a llevar a renta fincas de eclesiásticos. Todos los demás debían vender su fuerza de trabajo para obtener ingresos suficientes para la subsistencia familiar. El predominio de la pequeña propiedad campesina, en la práctica se reducía a un feroz minifundismo en cuyo seno se combinaban cientos de propietarios incapaces de lograr un producto sustancial y un pequeño grupo de ricos y labradores que podían prescindir del mercado de productos agrícolas.

Por otra parte, el tamaño medio de las parcelas resultaba muy exiguo. 15 áreas como media, 19 en las villas - por la mayor acumulación de propietarios medianos y grandes- y sólo 12 en las aldeas no son tamaños muy adecuados para estimular el crecimiento agrario. Nuevamente, este dato vuelve a ilustrar las oportunidades que ofrecía un medio hostil como pocos al cultivo de la tierra.

Con leves variaciones, la estructura de la propiedad de la tierra de los vecinos se reproducía entre los forasteros y los eclesiásticos: mayores desigualdades entre los forasteros, y una estructura un poco más equilibrada entre los eclesiásticos (cuadro 7). Con parcelas medias de mayor tamaño en ambos grupos, lo que ya indica una mejor calidad de los patrimonios de forasteros y clero, los dos constituyen un apartado digno de estudio. 
JOSE RAMÓN MORENO FERNÁNDEZ

Cuadro 7. Estructura de la propiedad de la tierra en las sierras de La Rioja, 1750

\begin{tabular}{|c|c|c|c|c|c|c|c|c|c|}
\hline \multirow{2}{*}{ Áreas } & \multicolumn{2}{|c|}{ Propietarios } & \multicolumn{2}{|c|}{ Fincas } & \multicolumn{2}{|c|}{ Extensión } & \multirow{2}{*}{$\begin{array}{c}\text { Ext. media } \\
\text { áreas }\end{array}$} & \multicolumn{2}{|c|}{ Producto } \\
\hline & $\mathrm{n}^{\mathrm{o}}$ & $\%$ & $n^{0}$ & $\%$ & hectáreas & $\%$ & & reales & $\%$ \\
\hline \multicolumn{10}{|l|}{ Vecinos } \\
\hline $0-20$ & 259 & 18,3 & 333 & 1,8 & 12,0 & 0,4 & 3,6 & $1.545,0$ & 0,7 \\
\hline $20,1-60$ & 226 & 16,0 & 775 & 4,2 & 85,3 & 3,0 & 11,0 & $6.312,2$ & 2,8 \\
\hline $60,1-100$ & 183 & 13,0 & 1.178 & 6,4 & 143,5 & 5,0 & 12,2 & $11.358,6$ & 5,0 \\
\hline $100,1-200$ & 285 & 20,2 & 3.406 & 18,4 & 418,4 & 14,7 & 12,3 & $33.374,5$ & 14,6 \\
\hline $200,1-500$ & 320 & 22,6 & 7.303 & 39,4 & $1.004,1$ & 35,3 & 13,8 & $77.179,9$ & 33,7 \\
\hline$>500$ & 140 & 9,9 & 5.544 & 29,9 & $1.182,6$ & 41,6 & 21,3 & $99.315,1$ & 43,4 \\
\hline Vecinos 1 & .413 & 100,0 & 18.539 & 100,0 & $2.846,0$ & 100,0 & 15,4 & $229.085,2$ & 100,0 \\
\hline \multicolumn{10}{|l|}{ Eclesiásticos } \\
\hline $0-20$ & 33 & 14,9 & 47 & 1,3 & 2,8 & 0,4 & 6,0 & 495,0 & 0,9 \\
\hline $20,1-60$ & 48 & 21,6 & 148 & 4,2 & 19,2 & 2,9 & 13,0 & $1.877,5$ & 3,4 \\
\hline $60,1-100$ & 19 & 8,6 & 94 & 2,7 & 15,5 & 2,3 & 16,5 & $1.229,3$ & 2,2 \\
\hline $100,1-200$ & 31 & 14,0 & 362 & 10,3 & 44,5 & 6,7 & 12,3 & $3.415,1$ & 6,1 \\
\hline $200,1-500$ & 56 & 25,2 & 957 & 27,3 & 178,8 & 26,9 & 18,7 & $14.633,5$ & 26,2 \\
\hline$>500$ & 35 & 15,8 & 1.899 & 54,1 & 403,6 & 60,7 & 21,3 & $34.149,5$ & 61,2 \\
\hline Eclesiásticos & 222 & 100,0 & 3.507 & 100,0 & 664,4 & 100,0 & 18,9 & $55.799,9$ & 100,0 \\
\hline \multicolumn{10}{|l|}{ Forasteros } \\
\hline $0-20$ & 39 & 14,3 & 44 & 2,2 & 4,1 & 1,1 & 9,3 & 312,1 & 1,0 \\
\hline $20,1-60$ & 95 & 34,8 & 267 & 13,4 & 34,0 & 8,8 & 12,7 & $2.560,5$ & 8,1 \\
\hline $60,1-100$ & 50 & 18,3 & 261 & 13,1 & 38,3 & 10,0 & 14,7 & $2.882,7$ & 9,1 \\
\hline $100,1-200$ & 54 & 19,8 & 476 & 23,9 & 75,1 & 19,5 & 15,8 & $5.551,2$ & 17,5 \\
\hline $200,1-500$ & 23 & 8,4 & 375 & 18,8 & 72,6 & 18,9 & 19,4 & $5.410,0$ & 17,0 \\
\hline$>500$ & 12 & 4,4 & 570 & 28,6 & 160,7 & 41,8 & 28,2 & $15.073,7$ & 47,4 \\
\hline Forasteros & 273 & 100,0 & 1.991 & 100,0 & 384,7 & 100,0 & 19,3 & $31.790,3$ & 100,0 \\
\hline \multicolumn{10}{|l|}{ Total sierras } \\
\hline $0-20$ & 331 & 17,3 & 424 & 1,8 & 18,9 & 0,5 & 4,5 & $2.352,1$ & 0,7 \\
\hline $20,1-60$ & 369 & 19,3 & 1.190 & 5,0 & 138,5 & 3,6 & 11,6 & $10.750,1$ & 3,4 \\
\hline $60,1-100$ & 252 & 13,2 & 1.532 & 6,4 & 197,3 & 5,1 & 12,9 & $15.470,6$ & 4,9 \\
\hline $100,1-200$ & 370 & 19,4 & 4.243 & 17,7 & 538,0 & 13,8 & 12,7 & $42.340,9$ & 13,4 \\
\hline $200,1-500$ & 399 & 20,9 & 8.635 & 35,9 & $1.255,5$ & 32,2 & 14,5 & $97.223,5$ & 30,7 \\
\hline$>500$ & 187 & 9,8 & 8.012 & 33,3 & $1.746,8$ & 44,8 & 21,8 & $148.538,3$ & 46,9 \\
\hline \multicolumn{2}{|c|}{ Sierras 1.908} & 100,0 & 24.037 & 100,0 & $3.895,1$ & 100,0 & 16,2 & $316.675,4$ & 100,0 \\
\hline
\end{tabular}

Fuente: AHPLR, Catastro, Respuestas particulares

\subsection{La propiedad de los forasteros.}

Los 273 forasteros que tenían propiedades en los pueblos que han servido para elaborar los cuadros, suponían el 14 por 100 de los propietarios, pero controlaban sólo un 10 por 100 de la tierra de cultivo ${ }^{20}$. Este porcentaje llegaba como máximo al 19 por 100 en Soto y al 14 en Villoslada, aunque en Lumbreras y Ortigosa no alcanzaba siquiera el 5 por 100 .

20. Para el análisis de los forasteros, he considerado como tales a todos los propietarios que residían en otras poblaciones, aunque fueran vecinos del lugar. Así, dos vecinos de Ezcaray, en paradero desconocido, se han separado de los vecinos. Al contrario, algunos habitantes y residentes -que no habían adquirido la vecindad- están incluidos entre los vecinos. 
LA PROPIEDAD DE LA TIERRA EN LA MONTAÑA RIOJANA A MEDIADOS DEL SIGLO XVIII

Cuadro 8. Lugar de vecindad de los forasteros propietarios, 1750

\begin{tabular}{lcrrrrrrrrrrr}
\hline & 0 & $*$ & \multicolumn{1}{c}{1} & $*$ & 2 & $*$ & 3 & $*$ & 4 & $*$ & 5 & $*$ \\
\hline Ezcaray & 3 & 3,1 & 44 & 39,0 & 2 & 1,2 & 7 & 29,8 & 8 & 26,9 & & \\
Lumbreras & & & & & 3 & 51,5 & & & 10 & 42,7 & 1 & 5,8 \\
Ortigosa & & & 5 & 18,8 & 2 & 8,4 & & & 2 & 72,8 & & \\
Soto & 16 & 16,0 & 116 & 56,5 & 18 & 10,9 & 3 & 5,7 & 6 & 8,4 & 3 & 2,5 \\
Villoslada & 4 & 8,4 & & & 3 & 69,5 & 1 & 0,8 & 5 & 21,4 & & \\
Viniegra de Abajo & & & 11 & 100,0 & & & & & & & & \\
\hline Total & 23 & 8,4 & 176 & 35,8 & 28 & 24,2 & 11 & 8,5 & 31 & 21,5 & 4 & 1,5 \\
\hline
\end{tabular}

1: vecinos de pueblos limítrofes. 2: Otros propietarios de la sierra. 3: propietarios del valle. 4: propietarios de lugares lejanos. 5: propietarios de Indias.

* Porcentaje de cada grupo de la superficie de la tierra de propiedad de forasteros.

Fuente: AHPLR, Catastro, respuestas particulares y libros de lo personal.

De ellos (cuadro 8), 176, el 64 por 100 , eran vecinos de pueblos limítrofes y, probablemente, cultivaban por sí mismos sus tierras. Estos, junto a los 28 vecinos de otros lugares de la sierra menos cercanos - lo necesario como para no permitir el desplazamiento diario para sostener un cultivo directo- constituían las tres cuartas partes de los propietarios forasteros. El resto residía en otras localidades de la provincia, en otras provincias e, incluso, en Indias. Llama la atención la ausencia de propietarios del valle, tanto en términos absolutos como relativos. Son pocos, tan sólo 11 , y muy pocos si los comparamos con los residentes en otras regiones -Soria y Burgos, naturalmente, pero también Madrid, Extremadura o Galicia-, que casi triplican su número. Esto reafirma una vez más la idea de que las sierras vivieron siempre de espaldas al valle, rompiendo con la manida concepción de la complementariedad valle-sierra.

Por otro lado, de forma un tanto sorprendente, en Lumbreras, Ortigosa y Villoslada no existen prácticamente propietarios avecindados en pueblos limítrofes. La razón se encuentra sin duda en la enorme presencia de la ganadería trashumante, precisamente en estos enclaves. Es posible deducir que aquellos pueblos con mayor dotación de terrenos concejiles para pastos concentraban las labores agrícolas en el ruedo de la población, de forma que se ampliaba la distancia entre las hojas de cultivo y las localidades vecinas, a la vez que se mantenía un control máximo sobre la salvaguarda de los pastos. Por otro lado, también indica la debilidad de las relaciones que se habían tejido con el entorno más próximo a partir de la oferta de trabajo en las cabañas trashumantes. En todo caso, me parece que demuestra la escasa expansión del terreno cultivado que se había producido en fechas tan avanzadas como 1750-1753.

En los pueblos como Soto y Treguajantes, con una vocación ganadera menos exagerada y con el cultivo más extendido en todo el término, sí era más habitual encontrar propietarios de pueblos cercanos -Trevijano, Luezas, Terroba, La Mongía, Ribalmaguillo-, tanto que en esta jurisdicción llegaban a poseer cerca de la quinta parte de la tierra de sembradura.

Por lo que se refiere a la calidad de la tierra que poseían los forasteros también hay materia para hacer algunas reflexiones. Globalmente el reparto de calidades parece similar al de los vecinos, con la excepción de las tierras incultas, de las que los foras- 
de la tierra eran también vecinos y descendientes de las familias más acaudaladas. Pareció existir una estrategia muy extendida -probablemente dirigida a evitar el fraccionamiento de los patrimonios- entre los poderosos que consistía en colocar a uno, o a varios, de los hijos varones en la iglesia. La fundación de capellanías y obras pías, en este contexto, no sería más que un recurso a la amortización de patrimonios para asegurar su continuidad.A efectos prácticos, pocas diferencias había entre el disfrute de un mayorazgo y la administración de una capellanía. En ambos casos, el vínculo tenía el objetivo de reservar una parte suficientemente nutrida del patrimonio para su disfrute por uno de los miembros de la familia.

La importancia de la propiedad del clero en La Rioja es difícil de encarecer. Cerca del 17 por 100 de la tierra cultivada y una porción levemente superior del producto agrícola total estaban en manos de instituciones eclesiásticas (cuadro 10). La superficie controlada por el clero era muy alta si la comparamos con el 14 por 100 del total de Castilla la Vieja, pero el porcentaje del producto, sin embargo, no es tan elevado como el correspondiente a toda la Corona de Castilla (sobre el 24 por 100 del producto) ni como el de Castilla la Vieja ( 23 por 100 del producto) ${ }^{22}$. La razón estriba en una circunstancia particular: en las sierras de La Rioja la calidad media de las tierras de los eclesiásticos no difería de la distribución general de calidades. Sin embargo, en zonas más agrícolas como lo es Castilla la Vieja, la calidad de la tierra del clero estaba por encima de la media, por lo que la parte del producto agrícola aumentaba mucho. Con superficies más modestas, los patrimonios eclesiásticos eran de los más productivos. En La Rioja, a pesar de los brillantes resultados en cuanto a cantidad de tierras, la iglesia no era especialmente rica.Y de hecho, en algunos lugares -Lumbreras, Villoslada y Viniegra de Abajo- incluso se puede afirmar que ocupaba un papel marginal como propietaria de tierras. A pesar de que los mayores porcentajes de tierras eclesiásticas aparecen en las heredades de mayor calidad como huertas y prados, el peso de la sembradura de secano, que no podía proporcionar más que pobres rendimientos, acaba moderando la importancia del producto en manos de la iglesia.

Claro que los datos de Castilla se elaboraron mediante los estados generales -letra D- y quizá comparar estos datos con los resultados de las respuestas particulares

Cuadro 10. La propiedad de la tierra del clero en las sierras de La Rioja, 1750*

\begin{tabular}{lcrrrrrrrrrrr}
\hline & \multicolumn{2}{c}{ Huerta } & \multicolumn{2}{c}{ Sembradura } & \multicolumn{2}{c}{ Prado } & \multicolumn{2}{c}{ Eras, incultas } & \multicolumn{2}{c}{ Total } & \multicolumn{2}{c}{ Producto } \\
& Has. & \multicolumn{1}{c}{$\%$} & \multicolumn{1}{c}{ Has. } & \multicolumn{1}{c}{$\%$} & Has. & \multicolumn{1}{c}{$\%$} & Has. & \multicolumn{1}{c}{$\%$} & Has. & $\%$ & reales & $\%$ \\
\hline Lumbreras y aldeas & 0,4 & 9,9 & 40,7 & 4,8 & 3,3 & 11,9 & 1,9 & 6,6 & 46,4 & 5,1 & 3.994 & 5,5 \\
Ezcaray y aldeas & 2,1 & 26,5 & 161,4 & 25,6 & 38,7 & 33,0 & 8,8 & 30,1 & 211,0 & 26,9 & 13.944 & 31,5 \\
Ortigosa y aldeas & 0,4 & 11,8 & 132,7 & 21,8 & 9,0 & 23,7 & 3,0 & 19,6 & 145,1 & 21,8 & 14.659 & 21,3 \\
Soto de Cameros & 4,7 & 38,9 & 129,6 & 18,3 & 0,0 & 0,0 & 25,5 & 67,5 & 159,8 & 21,1 & 13.561 & 21,5 \\
Villoslada & 0,3 & 12,0 & 73,3 & 14,0 & 7,1 & 25,3 & 3,8 & 18,7 & 84,5 & 14,7 & 8.648 & 15,4 \\
Viniegra de Abajo & 0,1 & 5,7 & 17,4 & 8,9 & 0,0 & 5,8 & 0,1 & 9,3 & 17,7 & 8,9 & 995 & 8,2 \\
\hline \multicolumn{1}{r}{ Total } & 8,1 & 25,0 & 555,1 & 15,8 & 58,1 & 27,5 & 36,8 & 27,7 & 658,0 & 16,9 & 55.800 & 17,6 \\
\hline
\end{tabular}

* El porcentaje se ha calculado sobre el total de tierras de cada categoría existentes en los términos municipales, excluida la propiedad del concejo.

Fuente: AHPLR, Catastro, Libros mayores de lo raíz de seculares y eclesiásticos.

22. Los datos de Castilla en GRUPO ‘75 (1977: 191). 
pueda no ser muy correcto. Para confrontar los datos de forma más fiable, hemos optado por incluir también aquéllos. Si sumamos las medidas de tierra que aparecen en el mapa $\mathrm{D}$ de los pueblos riojanos que pertenecían a la provincia de Soria obtenemos el cuadro 11:

Curiosamente, la situación se agrava. La iglesia poseía 37.176 medidas de tierras, de las que las tres cuartas partes correspondian a beneficiales y la cuarta parte restante a patrimoniales. El peso superficial de la tierra de los eclesiásticos se reduce al 8,5 por 100 en el valle y nada menos que al 2,7 por 100 en la sierra. Una extensión media en torno al 6 por 100 , incluso menor que la que se recogía en los datos del Grupo ' 75 para Galicia.Ahora bien, este resultado está distorsionado por la presencia de las tierras improductivas, de los montes y de los pastos. Las medidas de tierra con productos inferiores a un real de vellón eran nada menos que el 55 por 100 en el valle

Cuadro 11. Distribución de la propiedad de la tierra en La Rioja, 1750

\begin{tabular}{|c|c|c|c|c|c|c|}
\hline \multirow{2}{*}{$\begin{array}{l}\text { Propiedad según el } \\
\text { producto en reales }\end{array}$} & \multicolumn{3}{|c|}{ Seculares } & \multicolumn{3}{|c|}{ Eclesiásticos } \\
\hline & Medidas & I & II & Medidas & I & II \\
\hline \multicolumn{7}{|l|}{ Términos de valle } \\
\hline 120 y más & 4.160 & 77,21 & 1,31 & 1.228 & 22,79 & 4,15 \\
\hline $60-100$ & 18.600 & 75,96 & 5,87 & 5.885 & 24,04 & 19,89 \\
\hline $26-50$ & 57.559 & 81,98 & 18,15 & 12.648 & 18,02 & 42,75 \\
\hline $15-20$ & 51.457 & 88,62 & 16,23 & 6.610 & 11,38 & 22,34 \\
\hline de 3 a 10 & 11.166 & 94,57 & 3,52 & 641 & 5,43 & 2,17 \\
\hline $0,25-1$ & 23.210 & 99,23 & 7,32 & 180 & 0,77 & 0,61 \\
\hline 0 & 150.931 & 98,44 & 47,60 & 2.396 & 1,56 & 8,10 \\
\hline Total & 317.083 & 91,47 & 100,00 & 29.588 & 8,53 & 100,00 \\
\hline Total 2. & 142.942 & 84,11 & & 27.012 & 15,89 & \\
\hline \multicolumn{7}{|l|}{ Términos de sierra } \\
\hline 120 y más & 531 & 84,82 & 0,20 & 95 & 15,18 & 1,25 \\
\hline $60-100$ & 1.600 & 80,12 & 0,59 & 397 & 19,88 & 5,23 \\
\hline $26-50$ & 10.808 & 81,72 & 3,99 & 2.418 & 18,28 & 31,87 \\
\hline $15-20$ & 16.871 & 88,45 & 6,22 & 2.204 & 11,55 & 29,05 \\
\hline de 3 a 10 & 20.423 & 93,26 & 7,53 & 1.476 & 6,74 & 19,45 \\
\hline $0,25-1$ & 32.029 & 99,89 & 11,81 & 36 & 0,11 & 0,47 \\
\hline 0 & 188.951 & 99,49 & 69,67 & 962 & 0,51 & 12,68 \\
\hline Total & 271.213 & 97,28 & 100,00 & 7.588 & 2,72 & 100,00 \\
\hline Total 2. & 50.233 & 88,40 & & 6.590 & 11,60 & \\
\hline
\end{tabular}

I. Porcentaje sobre el total de medidas de cada categoría.

II. Porcentaje sobre el total de tierras de cada comarca.

El total 2 excluye las dos categorías inferiores, es decir, las tierras que rinden un producto inferior a 1 real.

Fuente: A.H.N., Hacienda, Mapa D del Catastro, Soria. 
LA PROPIEDAD DE IA TIERRA EN LA MONTAÑA RIOJANA A MEDIADOS DEL SIGLO XVIII

y el 80 por 100 en la sierra. Ninguna de ellas se cultivaba y el producto que rendían todas juntas no alcanzaba ni el 1 por 100 del producto bruto agrícola. Tenemos que eliminar de la tabla al menos estas categorías de tierras para obtener una imagen más fiel de los patrimonios territoriales del clero. Si lo hacemos, obtenemos un resultado que se aproxima más al reparto de la tierra cultivada. La fotografía es totalmente distinta y, a buen seguro, mucho más veridica: la propiedad eclesiástica de tierras cultivadas sube hasta el 16 por 100 en el valle y hasta el 11,5 en la sierra ${ }^{23}$.

La conclusión es casi inmediata: los eclesiásticos apenas poseían tierras incultas o de baja productividad.Además, en La Rioja, el peso de los montes era mucho más alto que la media de Castilla -sobre todo en la sierra, pero también en el valle-, lo que explica el bajisimo porcentaje de propiedad eclesiástica.

Ahora bien, el mejor indicador para calibrar la importancia de la iglesia como propietaria de tierras no es la cantidad de heredades que poseía, sino la parte del producto bruto agrícola que obtenía. El pastel se repartía de forma irregular: en el valle los eclesiásticos obtenían el 19,4 por 100, mientras en la sierra sólo percibían el 15,3 por 100. Pero las diferencias no quedaban ahí. En el valle, más del 50 por 100 del producto agrícola de eclesiásticos correspondía a tierras que rendían desde 60 reales por medida en adelante, mientras los legos sólo percibían el 39 por 100 del producto total de estas calidades de tierra. Así, en el valle se producía de forma muy evidente una selección de las mejores fincas por parte de los curas y las instituciones eclesiásticas. En la sierra, sin embargo, no hay tanta diferencia en cuanto a la calidad de los patrimonios: los eclesiásticos obtenían el 25 por 100 del producto de las tierras más ricas, pero los seculares llegaban al 20,5 por 100 . Sin duda el reparto del terrazgo era más homogéneo en la sierra en lo relativo a la calidad de las parcelas.

No obstante, esta visión macro oculta tanto como aclara. De hecho en el clero riojano convivían instituciones y clérigos que controlaban muy exiguas rentas agrícolas con unos pocos extraordinariamente ricos (cuadro 7). Había obras pías, capellanías y clérigos que apenas tenían dos o tres pequeñas parcelas mientras otros controlaban cantidades de tierra muy sustanciales.

De cualquier modo, la iglesia, como institución, no podía participar en el comercio o en la manufactura con la misma intensidad que los legos y, salvo en el caso de clérigos que disfrutaban de cabañas trashumantes en el concepto patrimonial, tampoco de la propiedad de ganados -con la muy notable excepción del monasterio de Valvanera-. La iglesia, pues, tenía por su propia naturaleza una composición de ingresos ligeramente distinta y, casi de forma obligada, la propiedad de la tierra había venido siendo en toda Castilla, el concepto principal sobre el que se asentaba su poder económico.

Ahora bien, tampoco conviene olvidar que, en las sierras, entre la rentas de la iglesia se contaba una abundante cantidad de ganados, pero sobre todo un volumen de

23. Por cierto que el GRUPO ' 75 no realizó esta operación, de modo que sus resultados deberían compararse simplemente con el total, sin ningún tipo de corrección. Si a los 83.492 .405 medidas de tierra de la Corona de Castilla les restamos casi 2 millones de tierras totalmente improductivas -con producción de 0 reales-, también los porcentajes de propiedad de los legos se modifican desde el 85,3 por 100 hasta el 81,8 . 
JOSÉ RAMÓN MORENO FERNÁNDEZ

Cuadro 12. Distribución del producto agrícola en La Rioja, 1750

\begin{tabular}{|c|c|c|c|c|c|c|}
\hline \multirow{2}{*}{$\begin{array}{l}\text { Propiedad según el } \\
\text { producto en reales }\end{array}$} & \multicolumn{3}{|c|}{ Seculares } & \multicolumn{3}{|c|}{ Eclesiásticos } \\
\hline & Producto & I & II & Producto & I & II \\
\hline \multicolumn{7}{|l|}{ Términos de valle } \\
\hline 120 y más & 631.520 & 75,89 & 12,77 & 200.600 & 24,11 & 16,89 \\
\hline $60-100$ & 1.312 .110 & 75,99 & 26,52 & 414.670 & 24,01 & 34,90 \\
\hline $26-50$ & 1.979 .758 & 81,55 & 40,02 & 448.048 & 18,45 & 37,71 \\
\hline $15-20$ & 949.660 & 88,74 & 19,20 & 120.560 & 11,26 & 10,15 \\
\hline de 3 a 10 & 63.044 & 94,11 & 1,27 & 3.946 & 5,89 & 0,33 \\
\hline $0,25-1$ & 10.963 & 98,38 & 0,22 & 180 & 1,62 & 0,02 \\
\hline Total & 4.947 .055 & 80,64 & 100,00 & 1.188 .004 & 19,36 & 100,00 \\
\hline \multicolumn{7}{|l|}{ Términos de sierra } \\
\hline 120 y más & 83.940 & 84,43 & 8,38 & 15.480 & 15,57 & 8,66 \\
\hline $60-100$ & 121.260 & 80,24 & 12,10 & 29.870 & 19,76 & 16,72 \\
\hline $26-50$ & 360.112 & 81,68 & 35,94 & 80.788 & 18,32 & 45,22 \\
\hline $15-20$ & 308.150 & 88,08 & 30,76 & 41.690 & 11,92 & 23,33 \\
\hline de 3 a 10 & 105.177 & 90,68 & 10,50 & 10.810 & 9,32 & 6,05 \\
\hline \multirow[t]{2}{*}{$0,25-1$} & 23.255 & 99,85 & 2,32 & 36 & 0,15 & 0,02 \\
\hline & 1.001 .894 & 84,87 & 100,00 & 178.674 & 15,13 & 100,00 \\
\hline
\end{tabular}

I. Porcentaje sobre el total de medidas de cada categoría.

II. Porcentaje sobre el total de tierras de cada comarca pertenecientes a cada grupo de propietarios.

Fuente: A.H.N., Hacienda, Mapa D del Catastro, Soria.

censos que podía alcanzar dimensiones espectaculares. Lógicamente, los ingresos eclesiásticos reproducían, hasta donde era posible, la estructura económica de las poblaciones en las que se movían y, donde la expansión agrícola era tan dificultosa como hemos visto, la tierra tenía que pasar a un segundo plano. Este es un asunto en el que no voy a entrar pormenorizadamente, pero baste señalar que en un caso extremo, el de Soto de Cameros, los eclesiásticos disfrutaban de más de 400 censos redimibles que producian por encima de $\operatorname{los} 12.000$ rs al año, una cifra cercana al producto bruto agrícola de sus tierras -al producto que realmente percibían aún habría que restarle lo que quedaba en manos de los renteros, así que los ingresos por censos estaban muy por encima-. Impuestos casi siempre contra inmuebles urbanos, era rara la casa de Soto que no estaba hipotecada con algún censo de variada cuantía. Indudablemente, la suma de los diezmos, del producto de los censos y del monto de aniversarios y memorias de misas superaba con mucho los ingresos brutos derivados de la propiedad de tierra de cultivo.Así pues, tanto entre el clero como entre los legos, la propiedad de la tierra no tenía una importancia ilimitada.

En Ezcaray podemos encontrar un ejemplo muy significativo. El mayor propietario territorial de todos los que aparecen en la muestra seleccionada era, sin duda, el cabil- 
do de Ezcaray (cuadro 13). El mayor por superficie poseída, era el segundo propietario en cuanto a producto bruto agrícola. Poseía nada menos que 55 hectáreas de tierra, casi en su totalidad cultivables, que rozaban los 4.000 reales de producto bruto. Afortunadamente, los libros mayores de lo raíz de Ezcaray son muy explícitos a la hora de recoger toda clase de ingresos de los eclesiásticos y ha sido posible reconstruir con cierta fidelidad la composición de los ingresos del cabildo ${ }^{24}$. Así podremos calibrar la importancia de la propiedad de la tierra para los ingresos del clero en el caso más extremo posible, aquel en el que su importancia tenía que ser máxima.

Naturalmente, los ingresos del cabildo no coincidían con el producto bruto que se había señalado a las tierras. Teniéndolas todas cedidas en arrendamiento, los haberes que percibía por su carácter de propietario consistían en el dinero líquido y las cantidades de grano que alcanzaba su valor en renta.Aquí no había posibilidad de engaño, dado que además se cruzaba la información del arrendador con la del arrendatario y sería impensable un acuerdo entre el cabildo y sus más de 60 renteros. Pues bien, por sus 55 hectáreas de tierra, el cabildo percibía anualmente 2.506 reales, que comparados con el total de sus ingresos, suponían menos del 15 por 100. De hecho, sólo mediante la suma de aniversarios y misas, el cabildo percibía más ingresos.

Es posible que, en términos nacionales, «el clero despertara menos críticas y envidias como diezmero que como rentista y propietario ${ }^{25}$, pero en estas sierras, en las que la calidad de la tierra no debía estimular mucho a una iglesia muy cauta a la hora de seleccionar sus preferencias, la importancia de los eclesiásticos como propietarios estaba lejos de resultar fundamental para sí mismos. Sin duda también sabía adaptarse

Cuadro 13. Composición de los ingresos netos del cabildo eclesiástico de Ezcaray, 1750

\begin{tabular}{|c|c|c|c|}
\hline & $\mathrm{n}^{\mathrm{o}}$ & reales & $\%$ \\
\hline Arrendamientos de tierras & 55,3 & $2.506,0$ & 14,67 \\
\hline Producto de casas & 9 & 366,0 & 2,14 \\
\hline Diezmos & & $9.118,0$ & 53,39 \\
\hline Censos & 65 & $2.030,6$ & 11,89 \\
\hline Aniversarios & 411 & $1.957,3$ & 11,46 \\
\hline \multirow[t]{2}{*}{ Misas rezadas } & & $1.099,8$ & 6,44 \\
\hline & & $17.077,7$ & 100 \\
\hline
\end{tabular}

Fuente: AHPLR, Catastro, respuestas particulares.

24. En ningún otro de los seis pueblos examinados se confesaban los ingresos percibidos en concepto de aniversarios y misas. En Ezcaray no sólo se incluyen, sino que nos consta que la declaración del cabildo se atenía escrupulosamente a la realidad. De hecho, el cabildo sólo había declarado 34 censos y los peritos, mediante una comprobación a partir de las declaraciones de los vecinos, añadieron 31 más que aparecían en las mismas.

25. VILAR, P. 1982: 68 
al terreno y en La Rioja optó por una composición patrimonial distinta a la que se podía ver en zonas con agriculturas dinámicas ${ }^{26}$.

\subsection{La propiedad agrícola de los concejos.}

Como es lógico, tratándose de municipios de montaña, la mayor parte del territorio permanecía sin roturar, bien por la fuerza de las condiciones ecológicas adversas, bien por la dedicación trashumante de algunas de las principales localidades. En La Rioja, por añadidura, la propiedad de las extensiones incultas estaba en su totalidad en manos de los concejos. No he podido encontrar, ni en las respuestas particulares ni en los memoriales, referencias a montes o pastos de titularidad individual ${ }^{27}$. Por consiguiente, la extensión de los bienes concejiles alcanzaba porcentajes del terrazgo muy elevados. Sin embargo, muy otra era la situación de la tierra de cultivo en manos de los concejos.

Cuadro 14. Composición de los bienes concejiles en las sierras, 1750

\begin{tabular}{lccccccccc}
\hline & \multicolumn{2}{c}{ Demanda } & \multicolumn{2}{c}{ Cameros } & \multicolumn{2}{c}{ Rioja Baja } & \multicolumn{2}{c}{ Total } \\
& Has. & $\%$ & Has. & $\%$ & Has. & $\%$ & Has. & $\%$ \\
\hline Tierra de cultivo & & & & & & & & \\
$\quad$ Hortaliza & 0,03 & 0,000 & 0,14 & 0,001 & 2,13 & 0,011 & 2,30 & 0,003 \\
Sembradura & 16,93 & 0,042 & 98,73 & 0,385 & 13,19 & 0,071 & 128,85 & 0,153 \\
Prados & 1,55 & 0,004 & 2,91 & 0,011 & 0 & 0 & 4,45 & 0,005 \\
Eras & 6,49 & 0,016 & 6,22 & 0,024 & 0 & 0 & 12,71 & 0,015 \\
& 25,0 & 0,06 & 108,0 & 0,42 & 15,3 & 0,08 & 148,3 & 0,18 \\
\hline \multicolumn{2}{l}{ Tierra sin cultivar $40.088,5$} & 99,94 & $25.542,0$ & 99,58 & $18.539,1$ & 99,92 & $84.169,6$ & 99,82 \\
\hline \multicolumn{2}{c}{ Total } & Total $40.113,4$ & 100 & $25.650,0$ & 100 & $18.554,4$ & 100 & $84.317,9$ & 100 \\
\hline
\end{tabular}

Fuente: AHPLR, Catastro, respuestas generales.

También la estructura de la propiedad concejil estaba aprisionada por las condiciones económicas de cada zona y, en cierto modo, las reproducía. En consecuencia, la tierra de cultivo en manos de los concejos era tan poca que para observar su porcentaje sobre el total de tierras concejiles (cuadro 14), en el caso de la hortaliza y los prados tenemos que ir hasta el tercer decimal.A todos los efectos, la superficie pública de cultivo se puede considerar despreciable. La muy respetable extensión de terrenos sin cultivar demuestra una vocación concejil de las tierras de aprovechamiento

26. Según el GRUPO ‘75 (1977: 197) la iglesia «tendía a radicar sus propiedades en las zonas agrícolamente privilegiadas de la Corona». Si esto era así, realmente no se les había perdido nada en las sierras.

27. Lo que no significa que no la hubiera en absoluto. Dado la esterilidad fiscal de tales terrenos, sería posible argumentar que también algunos montes de propiedad individual quedaron sin declarar. Sin embargo, sí existió un celo muy visible por incluir en el catastro aquellas superficies que se explotaban a cambio de dinero -los propios, en sentido estricto- o que reportaban una utilidad más allá de la subsistencia.Tampoco en los memoriales de los principales ganaderos y propietarios de tierras se recogen tales superficies. Me inclino por tanto a pensar que la totalidad de los montes -dehesas, pastos y bosques- pertenecían a los concejos ya fuera como propios o como comunales. 
ganadero y forestal y una identificación bastante aproximada entre los cultivos y las tierras de propiedad particular.

Pero no sólo las superficies de los terrenos de labor concejiles eran mínimas en relación a la superficie concejil total -cifra en la que se incluyen grandes extensiones de terrenos de pasto, de monte e incultos-, sino que también su peso era casi despreciable si lo relacionamos con el conjunto de la tierra de cultivo. La importancia de los cultivos en manos del concejo se puede ver mejor mediante las respuestas particulares (cuadro 15). En los pueblos de la muestra, las tierras de cultivos de propiedad concejil no alcanzan ni siquiera el 1 por 100: las huertas concejiles son sólo el 0,2 por 100 de las huertas, los secanos suponen un 0,4 por $100 \mathrm{y}$ los prados significan un exiguo 2,3 por 100. En total, el conjunto de los concejiles de estos pueblos, que componían la cuarta parte de la superficie de todas las sierras y que acaparaban mucho más del 77 por 100 de las tierras bajo su jurisdicción ${ }^{28}$, llegan a sumar menos de 20 hectáreas de tierra de cultivo. En la práctica, nada.

Cuadro 15. Composición de los bienes concejiles en las sierras, 1750

\begin{tabular}{|c|c|c|c|c|c|c|c|c|c|c|c|c|c|c|}
\hline & \multicolumn{2}{|c|}{ Hortaliza } & \multicolumn{2}{|c|}{ Sembradura } & \multicolumn{2}{|c|}{ Prados } & \multicolumn{2}{|c|}{ Eras } & \multicolumn{2}{|c|}{ Otras } & \multicolumn{2}{|c|}{ Total extensión } & \multicolumn{2}{|c|}{ Producto } \\
\hline & has. & $\%$ & has. & $\%$ & has. & $\%$ & has. & $\%$ & has. & $\%$ & has. & $\%$ & reales & $\%$ \\
\hline Ezcaray & 0,052 & 0,7 & 0,6 & 0,1 & 3,5 & 2,9 & 0,14 & 11,5 & 419,2 & 93,7 & 423,5 & 35,0 & $1.409,4$ & 3,1 \\
\hline Lumbreras & 0 & 0,0 & 1,6 & 0,2 & 0 & 0,0 & 0 & 0,0 & 403,5 & 93,4 & 405,1 & 30,7 & 170,0 & 0,2 \\
\hline Ortigosa & 0 & 0,0 & 1,5 & 0,2 & 0,5 & 1,4 & 0,04 & 100,0 & 201,5 & 92,9 & 203,5 & 23,4 & 254,4 & 0,4 \\
\hline Soto & 0,012 & 0,1 & 9,6 & 1,3 & 0 & 0,0 & 0 & 0,0 & $6.462,7$ & 99,4 & $6.472,3$ & 89,5 & $3.622,5$ & 5,4 \\
\hline Villoslada & 0 & 0,0 & 0 & 0,0 & 1,0 & 3,4 & 0 & 0,0 & $1.014,9$ & 98,1 & $1.015,8$ & 63,9 & $3.421,1$ & 5,7 \\
\hline Viniegra & 0,004 & 0,2 & 1,4 & 0,7 & 0 & 0,0 & 0 & 0,0 & $4.707,7$ & 100,0 & $4.709,1$ & 95,9 & $4.180,3$ & 25,7 \\
\hline Total & 0,068 & 0,2 & 14,7 & 0,4 & 5,0 & 2,3 & 0,18 & 4,6 & $13.209,4$ & 99,0 & $13.229,4$ & 77,3 & $13.057,8$ & 4,0 \\
\hline
\end{tabular}

Fuente: AHPLR, Catastro, respuestas particulares.

Da la impresión, por lo tanto, de que la propiedad individual y la propiedad colectiva resultaban, en gran medida, separadas por la misma frontera que había entre los terrenos sin cultivar y los cultivos. Aunque existieran algunos yermos por desidia -tierra de propiedad particular que se mantiene inculta, un 0,5 por 100 de los términosen manos de particulares, casi siempre forasteros y eclesiásticos, se puede identificar la tierra sin cultivar con el patrimonio concejil. A la inversa, aunque también los concejos poseían algunas medidas de tierra de cultivo, no era en un porcentaje como para que sea impropio decir que los cultivos se encontraban en manos particulares.Aspecto que se acentúa más todavía si percibimos la paradoja de que los mayores propietarios territoriales de las sierras, los concejos, que llegaban a controlar más de las tres cuartas partes de los términos municipales, tan sólo obtenían un 4 por 100 del producto bruto agrícola. La brillantez de los resultados superficiales contrasta vivamente con la mediocridad de las rentas obtenidas.

28. Aunque en el cuadro el porcęntaje es del 77 por 100, como se verá en el apartado dedicado a los montes y pastos, aún habría sido mucho mayor si las respuestas de Ezcaray, Lumbreras, Ortigosa y Villoslada hubieran recogido amplísimas extensiones de tierras incultas que dejaron de declarar por su carácter de fiscalmente improductivas. 


\section{RECAPITULACIÓN. LA AGRICULTURA, UNA CONTRIBUCIÓN A LA SUBSISTENCIA.}

En las sierras riojanas, la agricultura era una actividad marginal al menos por dos razones complementarias. Estaba lastrada, en primer lugar, por las dificultades orográficas, climáticas y edáficas que configuraban un entorno ecológico duro, poco apto para los cultivos. En segundo lugar, los complicados juegos de intereses que se daban cita en una zona especializada en el subsector pecuario bloqueaban la vía de la expansión de los cultivos. Sin embargo, la agricultura intervenía decisivamente en la configuración del complejo modelo productivo que funcionaba en las montañas.

Así las cosas, la propiedad de la tierra en las sierras de La Rioja no era el elemento clave de las relaciones de producción, aunque sí un aspecto a tener en cuenta. Las relaciones de producción estaban definidas por las que se establecían entre comerciantes y manufactureros o entre ganaderos y pastores, es decir, por las establecidas en torno a los mercados de trabajo y a la circulación de algunas mercancías. En las sierras, el propietario agrícola había cedido su preeminencia al gran ganadero y al rico comerciante -que en muchas ocasiones era las tres cosas a un tiempo-. De hecho, la gran mayoría de los serranos eran propietarios. La extensión de la propiedad, pequeña e ínfima, así como la existencia de superficies comunales de las que todos se beneficiaban, eran la última protección de las familias serranas frente a la proletarización que habría supuesto depender en exclusiva del mercado de trabajo. Desde el otro punto de vista, el de los poderosos, servía para mantener la paz social y para obtener las máximas ventajas de una mano de obra que contaba con algunos pequeños ingresos suplementarios. En definitiva, aunque por su aportación a la renta de las sierras la agricultura sólo puede ser calificada de marginal, la propiedad de la tierra y la dedicación al cultivo a tiempo parcial eran elementos muy importantes dentro de la estructura económica serrana. De una forma sutil y poco visible, la actividad agrícola formaba parte de un entramado productivo en el que no siempre es fácil deslindar dónde acaba lo sustantivo y dónde empieza lo adjetivo. 


\title{
BIBLIOGRAFÍA
}

\author{
ANES, G. 1989 \\ «Sociedad y economía», en Actas del Congreso Internacional sobre "Carlos III y la Ilus- \\ tración”. II. Economía y sociedad, Ministerio de Cultura, Madrid, pp. 1-138. \\ BERNAL, A.M. 1989 \\ "Las agriculturas de España en el siglo XVIII", en AA.VV., Estructuras agrarias $y$ reformis- \\ mo ilustrado en la España del siglo XVIII, M.A.P.A., Madrid, pp. 11-24.
}

COPPOLA, G. 1989

«La montagna alpina.Vocazioni originarie e trasformazioni funzionali», en P. Bevilacqua, ed., Storia dell'agricoltura italiana in età contemporanea. I. Spazi e paesaggi, Marsilio, Venecia, pp. 495-530.

DELGADO VIÑAS, C. 1983

«La explotación agraria y la organización del espacio en las Montañas de Burgos: la Merindad de Asturias de Santillana durante los siglos XVI al XVIII", en AA.VV., El pasado bistórico de Castilla y León. 2. Edad Moderna, Junta de Castilla y León, Burgos.

DOMÍNGUEZ ORTIZ,A. 1996

«La nobleza como estamento y grupo social en el siglo XVII», en AA.VV., Nobleza y sociedad en la España Moderna, Fundación Central Hispano, Oviedo, pp. 113-133.

GARCÍA FERNÁNDEZ, J. 1975

Organización del espacio y economía rural en la España atlántica, Siglo XXI, Madrid.

GÓMEZ URDÁÑ̃ZZ, J. L. 1986

«Subsistencia y descapitalización en el Camero Viejo al final del Antiguo Régimen», Cuadernos de Investigación Histórica Brocar, 12, pp.103-140.

GRUPO '75 1977

La economía del Antiguo Régimen. La "Renta Nacional" de la Corona de Castilla,U.A.M., Madrid.

IBÁÑEZ RODRÍGUEZ, S. 1995

Diezmo y primicia en la diócesis de Calahorra. Las fórmulas de participación eclesiástica en el producto agrario en La Rioja (siglos XVI al XVIII), Tesis doctoral inédita leída en la Universidad de La Rioja.

MADOZ, P. 1850

Diccionario Geográfico-Estadístico-Histórico de España y sus posesiones de Ultramar, Madrid.

MARCOS MARTÍN,A. 1989

«El crecimiento agrario castellano del siglo XVIII en el movimiento de larga duración. ¿Mito o realidad?", en AA.VV., Estructuras agrarias y reformismo ilustrado en la España del siglo XVIII, M.A.P.A., Madrid, pp. 133-1663.

MARTINEZ OLMEDO, L. 1946

Monografía de la Villa de Ortigosa de Cameros. Historia, geografía, geología, montes, iglesias, curiosidades, agricultura, industria, etcétera, Madrid, 1946. 
MORENO FERNÁNDEZ, J. R. 1994

El monte público en La Rioja durante los siglos XVIII y XIX: aproximación a la desarticulación del régimen comunal, Gobierno de La Rioja, Logroño.

PARKER, G. 1986

Europa en crisis. 1598-1648, Siglo XXI, Madrid.

PÉREZ ROMERO, E. 1995

Patrimonios comunales, ganadería trashumante y sociedad en la Tierra de Soria. Siglos XVIII-XIX, Junta de Castilla y León, Salamanca.

SÁNCHEZ SALAZAR, F 1988

"Medidas de superficie tradicionales y sus equivalencias con el sistema métrico decimal», Agricultura y Sociedad, 49, pp. 467-481.

VILAR, P. 1982

«Estructuras.Algunas lecciones del catastro de la Ensenada», en Hidalgos, amotinados y guerrilleros. Pueblo y poderes en la bistoria de España, Crítica, Barcelona, pp. 63-92.

YUN CASALILLA, B. 1987

Sobre la transición del feudalismo al capitalismo en Castilla. Economía y sociedad en Tierra de Campos (1500-1830), Junta de Castilla y León, Salamanca. 